This item was submitted to Loughborough's Research Repository by the author.

Items in Figshare are protected by copyright, with all rights reserved, unless otherwise indicated.

\title{
Tribological investigation into achieving skin-friendly artificial turf surfaces
}

PLEASE CITE THE PUBLISHED VERSION

http://dx.doi.org/10.1016/j.matdes.2015.09.033

\section{PUBLISHER}

(c) Elsevier

VERSION

AM (Accepted Manuscript)

\section{PUBLISHER STATEMENT}

This work is made available according to the conditions of the Creative Commons Attribution-NonCommercialNoDerivatives 4.0 International (CC BY-NC-ND 4.0) licence. Full details of this licence are available at: https://creativecommons.org/licenses/by-nc-nd/4.0/

\section{LICENCE}

CC BY-NC-ND 4.0

\section{REPOSITORY RECORD}

Tay, Sock P., Xiao Hu, Paul Fleming, and Steph Forrester. 2019. "Tribological Investigation into Achieving Skin-friendly Artificial Turf Surfaces”. figshare. https://hdl.handle.net/2134/20038. 


\section{Title}

Tribological investigation into achieving skin-friendly artificial turf surfaces

\section{Author names and affiliations}

Sock Peng TAY ${ }^{a, b, c}$ (sptay1@e.ntu.edu.sg); Xiao HU ${ }^{a, b}$ (asxhu@ntu.edu.sg); Paul FLEMING ${ }^{c}$ (p.r.fleming@lboro.ac.uk); Steph FORRESTER ${ }^{d}$ (s.forrester@lboro.ac.uk)

${ }^{a}$ Institute for Sports Research, and ${ }^{b}$ School of Materials Science \& Engineering, Nanyang Technological University, 50 Nanyang Avenue, Singapore 639798

${ }^{c}$ School of Civil and Building Engineering, Loughborough University, Loughborough LE11 3TU, Leicestershire, United Kingdom

${ }^{d}$ Sports Technology Institute, Loughborough University, 1 Oakwood Drive, Loughborough LE11 3QF, Leicestershire, United Kingdom

\section{Corresponding author}

Xiao HU (Prof)

Email: asxhu@ntu.edu.sg

Address: School of Materials Science \& Engineering, Nanyang Technological University, Block N4.1, Nanyang Avenue, Singapore 639798

Telephone: +65 67904610

Fax: +65 67909081

\section{Please cite this article as:}

Tay, S.P., Hu, X., Fleming, P. and Forrester, S., 2016. Tribological investigation into achieving skin-friendly artificial turf surfaces. Materials \& Design, 89, pp.177-182. 
Title: $\quad$ Tribological investigation into achieving skin-friendly artificial turf surfaces

Authors: $\quad$ Sock Peng Tay ${ }^{a, b, c}, \mathrm{Xiao} \mathrm{Hu}^{a, b}$, Paul Fleming ${ }^{a, c}$ and Steph Forrester ${ }^{a, d}$

\begin{abstract}
A main concern with artificial turfs is the increased incidences of skin abrasions compared to playing on natural grass. The proliferation of these surfaces draws attention to the skinfriendliness and related test methods of the products. This study focuses on the yarn component and explores the significance of tribopairs in identifying the skin-friendly property of hydrophilically-modified polypropylene. The frictional behaviour of poly(sulfobetaine methacrylate)-grafted substrates were studied under dry and hydrated conditions with standard steel tribotips, commonly used in frictional assessments. The measurements were repeated with tribotips made from silicone skin, used in large-scale artificial turf testing. Results showed that when hydrated, hydrophilic polymer brushes were successful in reducing silicone skin-sample friction by $75.8 \%$. Interestingly, when extended trials were conducted, a step-jump in the frictional values of highly-modified samples was observed, attributed to the diminishing hydrated layer with prolonged testing. In contrast, the standard steel tribotips were unable to discern the effects of surface grafting or hydration, measuring consistently low frictional values across all samples. This study highlights the importance of tribotip selection and introduces a bench-top test method that can potentially be used for the quantification of skin-friendliness of artificial turf yarns during product development stages.
\end{abstract}

\title{
Keywords
}

Reduced abrasion; skin-friendly; reduced skin friction; artificial turfs; polymer brushes

\section{Introduction}

Artificial turfs - systems comprising grass-like polymeric yarn carpets with rubber and/or sand infill - were introduced in the 1960s to address issues of natural grass fields arising primarily from high-intensity usage and arid climates [1]. With the rapidly increasing popularity of turf sports such as rugby and football, the introduction of an alternative playing surface that caters to the high participation rates [2,3] can potentially fuel the growth of these sport industries. Manufacturers are thus eager to jump onto the artificial turf bandwagon, introducing a wide array of products comprising of different infills and carpets. This results in a range of surface properties across turf products - that have varying impacts on player performances and injury rates.

Epidemiological injury studies have been a key tool in identifying underlying problems of artificial turf systems by relating injury patterns to surface properties. Such injury trends have implications on product development, for example, a shockpad was introduced beneath the turf carpet to provide force-reduction properties critical to injuries such as concussions in rugby $[1,4]$. While many studies have found that overall injury rates were comparable on both artificial turf and natural grass surfaces, several researchers have identified the higher risks of 
certain injury types occurring on artificial turfs. In particular, injuries to the lower extremities and minor injuries (zero down-time) were recorded to be more significant [5-8]. It is also evident that field-users still prefer playing on natural grass, citing negative perceptions such as the abrasiveness of artificial turfs on skin $[9,10]$.

Although softer polyolefin yarns were introduced in the 1970s to replace the tougher polyamides [1], recent studies still show higher rates of skin abrasions suffered on artificial turfs as compared to natural grass fields $[7,11,12]$. Meyers et al. found that even when the test samples were marketed as "nonabrasive", the incidences of abrasions, contusions and lacerations sustained on these surfaces were significantly higher than that on natural fields (42.5\% vs. $29.6 \%$ of all injuries, respectively) [11]. Apart from the adoption of polyolefins for the manufacturing of artificial turf yarns, there has been little progress in the development of turf systems to reduce skin abrasiveness. Patented yarn technologies marketed as skinfriendly mostly attribute the claimed property to the use of polyolefins [13-16], while frictional assessments to support their skin-friendly claims are lacking.

The friction and abrasive properties of artificial turf surfaces currently follow the industry standard of the FIFA-08 test, developed by the football governing body Fédération Internationale de Football Association (FIFA) as part of the Quality Concept for accrediting artificial turfs. The lab-based test involves the use of a Securisport Sports Surface Tester that runs a silicone skin-attached foot across a $1 \mathrm{~m}^{2}$ prepared artificial turf surface to measure its coefficient of friction and skin abrasion value [17]. According to the Quality Concept, the product is satisfactory if the coefficient of friction falls between $0.35-0.75$ and produces a skin abrasion value of $\pm 30 \%$. Like the other standards in the FIFA Quality Concept, there is no justification on how the performance requirements have been determined.

The American Society for Testing and Materials (ASTM) has also published testing procedure ASTM ID: F1015 that assigns test surfaces with an Abrasiveness Index (AI) by measuring the decrease in mass of a friable foam block after being pulled across an artificial turf surface under a constant normal load [18]. However, the ASTM test does not provide an interpretation of the AI in relation to acceptable skin-friendly values. This method is also not commonly used as the foam block is seen as a poor representation of the human skin, questioning the relevance of the test. Both test methods measure the frictional properties of complete artificial turf systems but there has yet to be a standard procedure for the assessment of the abrasiveness of turf yarns, which is beneficial in the product development stages.

The lack of a standard test counter-surface poses as a limitation to effective and reliable standards for skin-friction assessment. For example, commercial product Sport Court ® SportGame $^{\mathrm{TM}}$ is marketed as a synthetic surface suitable for outdoor multi-sport uses with "low abrasion for safe play" [19]. However, the friction of the product was assessed using ASTM ID: C1028 - a standard for frictional measurements of ceramic tiles and like surfaces, using a Neolite sled as a counter-surface [20] where Neolite is a synthetic acrylic-based material commonly used for the manufacturing of shoe soles. Such qualification of products using testing standards not in accordance to their intended applications may lead to the compromising of consumer safety. 
This paper aims to contribute to the understanding of skin-turf friction by introducing a bench-top set-up that can potentially be used for the characterization of skin-friendliness - a test that is currently lacking in the industry. Attention is drawn to the selection of tribotips for the characterization process, highlighting the importance of appropriate test tips in identifying key frictional features of samples that are representative of skin-sample interaction. The skinfriendly samples used in the experiments were polypropylene (PP) substrates modified with hydrophilic sulfobetaine methacrylate polymer (pSBMA) brushes. Zwitterionic pSBMA is known for its antifouling properties capable of resisting the surface adsorption of pathogenic bacteria [21,22] and is superhydrophilic which provides hydration lubrication $[23,24]$ that reduces skin-sample friction. The study involves the use of skin-equivalent L7350 silicone [25] and commonly used standard AISI 440 stainless steel (SS) as tribotips to investigate the frictional properties of the modified samples and polypropylene controls. In the subsequent discussion, we relate the abrasiveness of a surface directly to its frictional property as excessive friction may lead to the lesion of the epidermis [26], resulting in a wound known as an abrasion [27].

\section{Materials and Methods}

The photoinduced surface grafting of pSBMA onto polypropylene substrates was carried out in accordance to previous work that studied the effect of pSBMA-grafting on creating skinfriendly surfaces. Commercial PP films of $0.03 \mathrm{~mm}$ were purchased from Goodfellow Inc. of Cambridge, UK and cut into 0.3 by $2.5 \mathrm{~cm}$ samples. The samples were cleaned by sonication with acetone for three repetitions to remove any residual organic contaminants and allowed to dry at room temperature. Sulfobetaine methacrylate (SBMA) monomer was purchased from Sigma-Aldrich together with photoinitiator benzophenone (BP). All other solvents were used as received.

\subsection{Surface-Modified Polypropylene for Friction Assessment}

Surface grafting with pSBMA brushes has been identified as an effective strategy to modify the frictional and anti-bacterial properties of PP substrates. The experiments were adapted from the approach used by Yang and Ranby [28-30]: where surface grafting of poly-SBMA onto the PP substrates was carried out using the Incure F200P UV Flood Curing Lamp equipped with a metal halide lamp (600W) at an irradiation intensity of $50 \mathrm{~mW} / \mathrm{cm}^{2}$ $\left( \pm 5 \mathrm{~mW} / \mathrm{cm}^{2}\right)$. A monomer solution of $0.20 \mathrm{M}$ was prepared by dissolving SBMA in degassed deionized water. The PP substrates were submerged in a $0.48 \mathrm{M}$ BP solution for $30 \mathrm{~min}$ to allow for the physiosorption of the photoinitiators onto the PP surfaces. The treated substrates were then dried in the dark for $4 \mathrm{~h}$. A $100 \mu \mathrm{L}$ drop of monomer solution was then deposited onto the BP-coated substrate using a micropipette and a pristine PP film of the same dimension was placed on top of the droplet, forming a sandwich structure. The assembly was then placed under the UV source. The degree of skin-friendliness of a surface can be controlled through the extent of polymerization hence, a series of samples with varying grafting extents were prepared for this study, with irradiation durations of $0,300,600,900$ and 1200s. 
The irradiated sandwich structure was delaminated in hot deionized water and the PP cover (not treated with BP) was discarded. The modified PP substrates were washed thoroughly with hot deionized water to remove homopolymers and residual monomers. The washed samples were then dried in vacuo overnight and stored in desiccators for further frictional analyses. The sample preparation process is summarized in Figure 1.

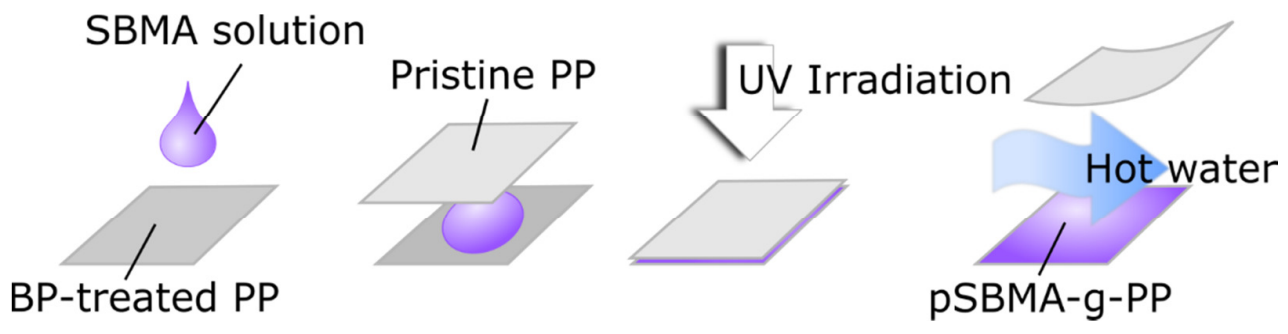

Figure 1 Schematic of sample preparation of pSBMA-grafted PP samples.

\subsection{Friction Studies}

To demonstrate the influence of counter-surface materials on the measured friction in relation to skin-friendliness of a surface, standard SS commonly used in tribological analysis [32-34] was selected as a basis of comparison against a skin-equivalent silicone rubber [25]. Under the limitations of performing in vivo frictional measurements on humans due to the large variability in skin properties [35,36] and ethical considerations, silicone was selected as it provides the closest replication of skin frictional behaviour amongst common materials [37].

The coefficient of friction $(\mu)$ of the samples were measured using the CSM Instruments SA Microtribometer with standard 1 cm-diameter AISI 440 SS balls and $1 \mathrm{~cm}$-diameter round tips of L7350 silicone skin. The silicone skin purchased from Maag Technic AG, Switzerland is the FIFA-selected counter-surface for assessing skin friction of artificial turf surfaces in accordance to their Handbook of Test Methods for Football Turf [17]. Frictional measurements were performed at room temperature $\left(25^{\circ} \mathrm{C}\right)$ with a normal load of $0.2 \mathrm{~N}$, rotational radius of $1.00 \mathrm{~mm}$ and a linear speed of $5 \mathrm{~cm} / \mathrm{s}$ for 300 laps. The test parameters were selected to produce contact pressures in the range of that experienced by players sliding on artificial turf surfaces [31]. The samples of varying grafting extents, were tested in both dry and hydrated states where the hydrated samples were equilibrated in deionized water for $2 \mathrm{~h}$ and excess surface moisture removed using a piece of filter paper prior to the tribological studies. Further tests were conducted on the hydrated samples by repeating the frictional measurements for 2000 laps, with all other variables held constant. The measurements were repeated five times for each sample under the respective conditions, and the average values are presented.

\section{Results}

Figure 2 shows the average coefficients of friction $(\mu)$ of the samples after 300 laps. Under dry conditions, it was observed that the $\mu$ values decreased slightly with irradiation time from 0 s to $600 \mathrm{~s}$, then increased to consistent values of around 0.50 when tested against a standard 
SS tribotip Figure 2a. The average $\mu$ values of the samples showed no significant changes when tested under hydrated conditions, with the surfaces modified for 0 s to 600s exhibiting higher frictions whereas and those modified for 900s and 1200s having lower $\mu$ values than that measured in the absence of hydration.

A similar trend was observed for the dried samples when tested using the L7350 silicone rubber tips (Figure $2 \mathrm{~b}$ ) with increasing $\mu$ values for irradiation times from $0 \mathrm{~s}$ to $600 \mathrm{~s}$, and subsequent values averaging at 1.20 (irradiation time $=900 \mathrm{~s}$ and $1200 \mathrm{~s}$ ). In general, the $\mu$ values measured using the silicone tip were significantly higher than that by the stainless steel tribotips - with magnitudes of at least two times that when measured with steel tips. In the presence of surface hydration, samples that have been modified for 0s and 300s showed slight decrease in $\mu$ values by $7.2 \%$ and $7.7 \%$ respectively. In contrast, large reductions in $\mu$ values were measured for samples that have been irradiated for $600 \mathrm{~s}$ or more. The highly-modified samples exhibited $\mu$ values up to $75.8 \%$ lower than that under dry conditions. The low frictional values of the hydrated modified surfaces are comparable to the values obtained when tested with stainless steel tips.

When the number of rotations on the microtribometer was increased to 2000, frictional profiles of the hydrated samples tested using both tribotips are shown in Figure 3. While the $\mu$ values of the samples tested using steel tribotips remained relatively constant over the 2000 cycles (Figure $3 \mathrm{a}-\mathrm{e}$ ), a drying effect was observed for the pSBMA-grafted samples irradiated for more than 600s (Figure $3 \mathrm{~h}-\mathrm{j}$ ). This drying effect is described by an initial phase of low frictional values $(\mu \leq 0.5)$, followed by a sharp increase in the coefficient of friction to values higher than 1.0. The low- $\mu$ phase of the highly-modified samples $(600 \mathrm{~s}-$ 1200s) lasted for $50-100$ s on average, corresponding to the L7350 tribotip traversing the sample surface for a distance of $2-4 \mathrm{~m}$. It is observed that at the mark of the $300^{\text {th }}$ lap, $\mu$ values correspond to the frictional trends concluded from the shorter trials. The variation of the initial and final $\mu$ values with respect to the extent of surface modification is presented in Figure 4. It is noted that the "final phase" $\mu$ values exceed the friction measured for the same samples under dry conditions.
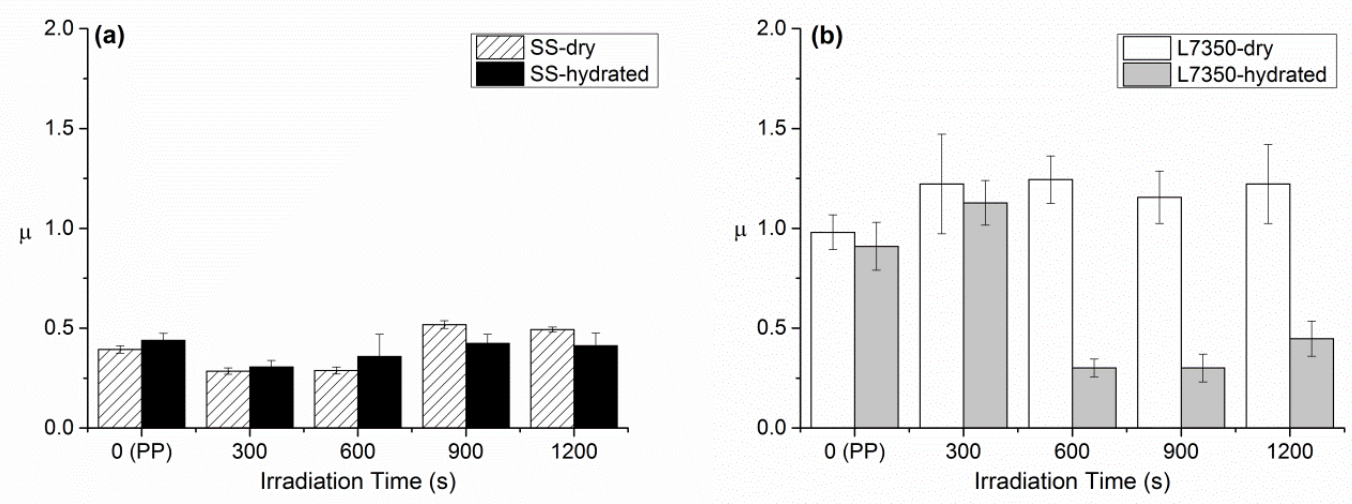

Figure 2 Comparison of average $\mu$ values between dry and hydrated surfaces of PP substrates and pSBMA-g-PP samples against (a) standard AISI 440 stainless steel (SS) tribotips and (b) L7350 silicone rubber skin tribotips 

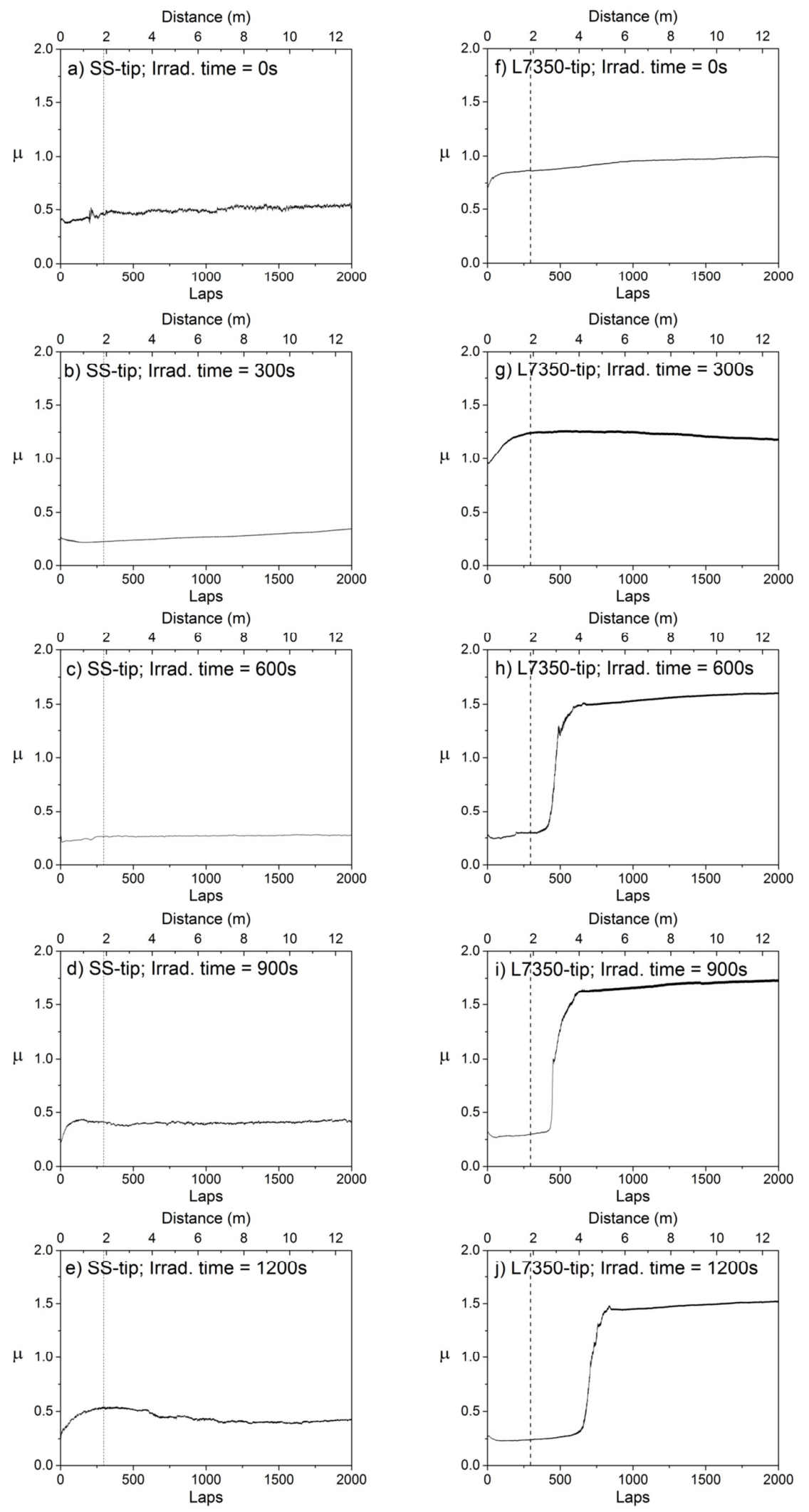

Figure 3 Sample frictional profiles for the surfaces tested for 2000 laps under hydrated conditions where (a) (e) are for measurements conducted using the SS tribotip and (f) - (j) with the L7350 silicone rubber tip (perforated lines indicate the $300^{\text {th }}$ lap-mark. The corresponding distance traversed by the tribotip over the sample (in metres) is also included. 


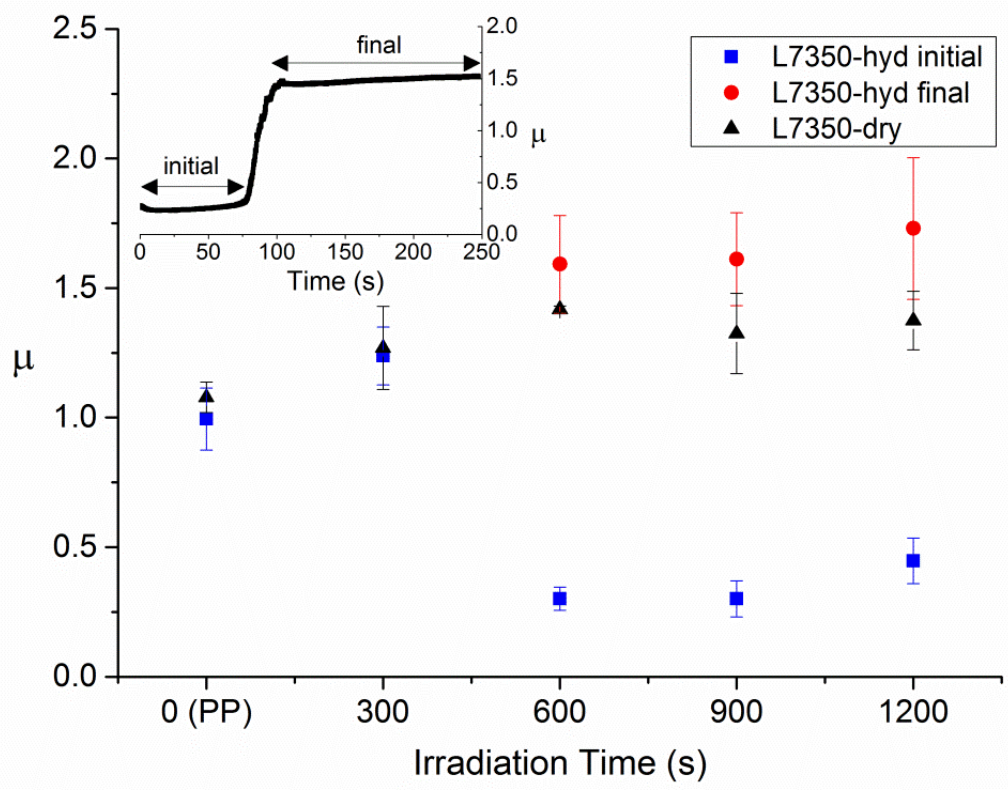

Figure 4 Variation of the initial and final coefficients of friction of the hydrated samples as tested using the L7350 silicone rubber tribotip. As samples irradiated for 0 s and 300s displayed no drying effect, the average $\mu$ values over the 2000 laps are shown. Data from the tests conducted under dry conditions are also shown $(\boldsymbol{\Delta})$.

\section{Discussion}

The frictional studies on the same samples using different tribotips led to contrasting conclusions on their frictional properties. When the tribological measurements were conducted using steel tribotips, consistently low $\mu$ values were obtained regardless of the presence of hydration, across all tested samples. This may be attributed to the ploughing mechanism [37,38] of friction dominating at the tip-sample interface, where the hard SS tips dig into the polymer samples resulting in the formation of a wear track and corresponding debris - evident on all tested samples even at low normal loading. The measured $\mu$ value is hence largely dependent on the material properties of the underlying substrate (polyprolylene). For example, the degree of crystallinity, presence of fillers and hardness are factors influencing the substrate's resistance to wear.

Measurements made with L7350 silicone rubber tips yielded interesting results. The effect of surface modification with pSBMA brushes was prominent under hydrated conditions where PP substrates irradiated for at least 600s showed a drastic decrease in $\mu$ values. The low frictional values are a result of the strong hydrating properties of the pSBMA brushes. In the presence of water, the superhydrophilic polymer brushes swell and extend into the solvent, binding the water molecules via strong electrostatic forces to form a stable hydrated layer $[23,24]$. This water-polymer system acts as a lubricating layer that effectively reduces the friction experienced at the tip-sample interface. 
Extended trials were conducted to investigate the stability of the hydrated layer, and surface friction with prolonged interfacial interaction. As the number of rotations was increased to 2000 , the effect of surface hydration diminishes and the measured $\mu$ values increase rapidly to values that are higher than when tested under dry conditions. This frictional behaviour is explained by the drying effect where water is evaporated from the sample surface due to heat produced from the continuous frictional action by the L7350 tribotip. Residual water molecules present at the tip-sample interface results in increased friction as the amount of hydration is insufficient to form an appreciable lubricating layer. This is similar to the effect of epidermal hydration where dry skin was found to have lower friction than moistened skin $[36,39,40]$, and excess hydration is capable of reducing skin friction due to the lubricating effect [36].

The tribological results show that frictional values measured using the stainless steel tips are insensitive to the surface modified samples, unable to distinguish between the PP substrate and the grafted samples. Due to the different friction mechanisms between steel-sample and silicone-sample tribopairs, the skin-surface interaction experienced when a player slides across an artificial turf will be more closely modelled by the latter - which involves the tribology of two soft compliant surfaces. This implies that the friction values measured with the steel tips are not appropriate for characterizing the skin-friendliness of soft polymeric surfaces, as in the case of artificial turf yarns.

The lubricating properties of hydrophilic polymer brushes have been well studied showing the effectiveness of different polymers in reducing interfacial friction [25,41,42]. However, the experimental set-ups used in these studies were such that the contacting interfaces were fully submerged in an aqueous environment, in the presence of excess lubricant. Hence issues regarding the hydration ability of the polymer brushes or the stability of the hydrated layer were not of concern. In the real-life circumstances of player-artificial turf interactions, the playing surfaces are often watered before a game but a sub-surface drainage system prevents water pooling on the surface - an undesirable condition that affects playing conditions $[43,44]$. This state of hydration is simulated in this study by the removal of excess surface water prior to frictional measurements which were conducted under ambient conditions. The results from the skin-equivalent silicone tips suggest that samples with sufficient pSBMAmodification are capable of maintaining strong adsorption of the water molecules, for up to an equivalent distance of $4 \mathrm{~m}$ traversed by the tip on the sample before the drying effect occurs.

This observation provides insights to how the skin-friendliness of the modified surfaces may be dependent on the "water retention" ability of the hydrophilic polymer brushes and paves the way to future work exploring approaches to improve the stability of the hydrated layer so as to provide a consistently low-skin-friction surface for durations lasting the span of a football game. 


\section{Conclusion}

Tribological studies were carried out on skin-friendly pSBMA-g-PP samples, using standard steel and skin-equivalent tribotips. When studying skin-friendliness of artificial turf surfaces, it is essential to select relevant tribopairs that simulate the interaction between human skin and turf yarns. Although commonly used as a standard testing material for frictional measurements in the industry, the use of stainless steel tips is inappropriate for our study. Whereas testing with silicone rubber tribotips offered insights to how the pSBMA modification may be effective in decreasing skin-turf friction through the formation of a lubricating hydrated layer, reducing frictional values by up to $75.8 \%$ when compared to dry samples. Results from the silicone tips also highlighted the limited effect of reduced-friction, as frictional values increase drastically when the hydrating layer diminishes due to prolonged friction testing. This study draws attention to the need for careful selection of test methods when assessing skin-friendliness of sports surfaces to prevent erroneous product qualifications. The simple experimental set-up using silicone rubber tribotips may potentially be enhanced for the use as an intermediate product assessment tool in the manufacturing of skin-friendly artificial turf surfaces.

\section{Acknowledgements}

The authors would like to thank the Energy Research Institute, Nanyang Technology University (ERI@N) for kindly providing access to the microtribometer. This study is part of a Ph. D. program under the Institute for Sports Research (ISR), Nanyang Technological University, Singapore.

\section{References}

[1] P. Fleming, Artificial turf systems for sport surfaces: current knowledge and research needs, Proc. Inst. Mech. Eng. Part P J. Sport. Eng. Techonology. 225 (2011) 43-62.

[2] J. Dvorak, A. Junge, T. Graf-Baumann, L. Peterson, Football is the most popular sport in the world, Am. J. Sports Med. 32 (2004) 3S-4S.

[3] A. Junge, J. Dvorak, Soccer injuries: a review on incidence and prevention, Sport. Med. 34 (2004) 929-938.

[4] International Rugby Board (IRB), IRB Artificial Rugby Turf Performance Specification, (2012).

[5] J. Bjørneboe, R. Bahr, T.E. Andersen, Risk of injury on third-generation artificial turf in Norwegian professional football, Br. J. Sports Med. 44 (2010) 794-798.

[6] J. Ekstrand, T. Timpka, M. Hägglund, Risk of injury in elite football played on artificial turf versus natural grass: A prospective two-cohort study, Br. J. Sports Med. 40 (2006) 975-980. 
[7] C.W. Fuller, L. Clarke, M.G. Molloy, Risk of injury associated with rugby union played on artificial turf, J. Sports Sci. 28 (2010) 563-570.

[8] S. Akkaya, M. Serinken, N. Akkaya, İ. Türkçüer, E. Uyanık, Football injuries on synthetic turf fields, Jt. Dis. Relat. Surg. 22 (2011) 155-159.

[9] E.M. Zanetti, Amateur football game on artificial turf: players' perceptions, Appl. Ergon. 40 (2009) 485-490.

[10] P. Burillo, L. Gallardo, J.L. Felipe, A.M. Gallardo, Artificial turf surfaces: Perception of safety, sporting feature, satisfaction and preference of football users, Eur. J. Sport Sci. 14 (2014) S437-S447.

[11] M.C. Meyers, B.S. Barnhill, Incidence, causes, and severity of high school football injuries on FieldTurf versus natural grass: a 5-year prospective study, Am. J. Sports Med. 32 (2004) 1626-1638.

[12] C.W. Fuller, R.W. Dick, J. Corlette, R. Schmalz, Comparison of the incidence, nature and cause of injuries sustained on grass and new generation artificial turf by male and female football players. Part 2: training injuries, Br. J. Sports Med. 41 Suppl 1 (2007) i27-32.

[13] E. Buriani, F. Zenoni, Thermoplastic synthetic fiber for producing artificial grass mats or the like, process for the production thereof and mats incorporating said fiber, WO 2008098905 A2, 2008.

[14] W. Olde, G.B. Slootweg, D. Van, L. Welzen, C. Widdershoven, Artificial fibre as well as an artificial lawn for sports fields provided with such fibre, EP1378592 A1, 2004.

[15] R. Luijkx, Artificial grass, US20130273268 A1, 2013.

[16] F. Atsma, D. Wildschut, Yarn for an artificial turf ground cover, artificial turf ground cover and playing field including such a yarn and method for producing such a yarn, US 7611763 B2, 2009.

[17] Fédération Internationale de Football Association (FIFA), FIFA Quality Concept for Football Turf - Handbook of Test Methods, 2012.

[18] ASTM International, ASTM Standard F 1015, 2003 (2009), Stand. Test Method Relat. Abrasiveness Synth. Turf Play. Surfaces. (2009).

[19] Sport Court, Product Information on Sports Surfaces I Sport Court, (2014). http://www.sportcourt.com/product-information (accessed April 17, 2015).

[20] ASTM International, ASTM Standard C1028 - 07e1, 2007, Stand. Test Method Determ. Static Coeff. Frict. Ceram. Tile Other Like Surfaces by Horiz. Dynamom. Pull-M. Method. (2007). 
[21] Z. Zhang, S. Chen, Y. Chang, S. Jiang, Surface Grafted Sulfobetaine Polymers via Atom Transfer Radical Polymerization as Superlow Fouling Coatings, J. Phys. Chem. B. 110 (2006) 10799-10804.

[22] Y.-H. Zhao, K.-H. Wee, R. Bai, Highly hydrophilic and low-protein-fouling polypropylene membrane prepared by surface modification with sulfobetaine-based zwitterionic polymer through a combined surface polymerization method, J. Memb. Sci. 362 (2010) 326-333.

[23] U. Raviv, S. Giasson, N. Kampf, J.-F. Gohy, R. Jérôme, J. Klein, Lubrication by charged polymers, Nature. 425 (2003) 163-165.

[24] M. Chen, W.H. Briscoe, S.P. Armes, J. Klein, Lubrication at physiological pressures by polyzwitterionic brushes, Science (80-. ). 323 (2009) 1698-1701.

[25] E. van der Heide, C.M. Lossie, K.J.C. Van Bommel, S. a. F. Reinders, H.B.M. Lenting, Experimental investigation of a polymer coating in sliding contact with skin-equivalent silicone rubber in an aqueous environment, Tribol. Trans. 53 (2010) 842-847.

[26] A. Metelitsa, B. Barankin, A.N. Lin, Diagnosis of sports-related dermatoses, Int. J. Dermatol. 43 (2004) 113-119.

[27] J. Fultz, P. Sturt, Mosby's Emergency Nursing Reference, 3rd ed., Elsevier Mosby, 2005.

[28] W.T. Yang, B. Ranby, Bulk surface photografting process and its applications. I. Reactions and kinetics, J. Appl. Polym. Sci. 62 (1996) 533-543.

[29] W.T. Yang, B. Ranby, Bulk surface photografting process and its applications. II. Principal factors affecting surface photografting, J. Appl. Polym. Sci. 62 (1996) 545555.

[30] B. Ranby, W.T. Yang, O. Tretinnikov, Surface photografting of polymer fibers, films and sheets, Nucl. Instruments Methods Phys. Res. Sect. B Beam Interact. with Mater. Atoms. 151 (1999) 301-305.

[31] W. van den Eijnde, M. Peppelman, M.O. Weghuis, P.E.J. van Erp, Psychosensorial assessment of skin damage caused by a sliding on artificial turf: The development and validation of a skin damage area and severity index, J. Sci. Med. Sport. 17 (2014) 1822.

[32] J. de Vicente, J.R. Stokes, H. a. Spikes, The frictional properties of Newtonian fluids in rolling - Sliding soft-EHL contact, Tribol. Lett. 20 (2005) 273-286.

[33] R.K. Sivamani, J. Goodman, N. V Gitis, H.I. Maibach, Friction coefficient of skin in real-time., Ski. Res. Technol. 9 (2003) 235-239.

[34] A.F. El-Shimi, In vivo skin friciton measurements, J. Soc. Cosmet. Chem. 28 (1977) $37-51$. 
[35] S. Derler, L.C. Gerhardt, Tribology of Skin: Review and Analysis of Experimental Results for the Friction Coefficient of Human Skin, Tribol. Lett. 45 (2012) 1-27.

[36] R.K. Sivamani, J. Goodman, N. V Gitis, H.I. Maibach, Coefficient of friction: tribological studies in man - an overview, Ski. Res. Technol. 9 (2003) 227-234.

[37] M. Zhang, A.F.T. Mak, In vivo friction properties of human skin, Prosthet. Orthot. Int. 23 (1999) 135-141.

[38] K. Holmberg, Coatings Tribology: Properties, Techniques, and Applications in Surface Engineering, Elsevier, 1994.

[39] L.-C. Gerhardt, V. Strässle, a Lenz, N.D. Spencer, S. Derler, Influence of epidermal hydration on the friction of human skin against textiles., J. R. Soc. Interface. 5 (2008) $1317-1328$.

[40] M.J. Adams, B.J. Briscoe, S.A. Johnson, Friction and lubrication of human skin, Tribol. Lett. 26 (2007) 239-253.

[41] T. Moro, Y. Takatori, K. Ishihara, T. Konno, Y. Takigawa, T. Matsushita, et al., Surface grafting of artificial joints with a biocompatible polymer for preventing periprosthetic osteolysis, Nat. Mater. 3 (2004) 829-836.

[42] K. Ishihara, Y. Iwasaki, S. Ebihara, Y. Shindo, N. Nakabayashi, Photoinduced graft polymerization of 2-methacryloyloxyethyl phosphorylcholine on polyethylene membrane surface for obtaining blood cell adhesion resistance, Colloids Surfaces B Biointerfaces. 18 (2000) 325-335.

[43] K. Severn, Science of Synthetic Turf Surfaces: Player-Surface Interactions, Loughborough University, 2010.

[44] A.J. McLeod, The management and maintenance of second generation sand-filled synthetic sports pitches, School of Applied Sciences, 2008. 